\title{
Hypomagnesaemia and Mortality in Dialysis
}

\author{
Gomez Lujan, Martin* \\ Department of Nephrology, Universidad Peruana de Ciencias Aplicadas, Perú
}

*Corresponding author: Gomez Lujan Martin, Department of Nephrology, Hospital E. Rebagliati, Essalud, Universidad Peruana de Ciencias Aplicadas, 525 Coronel Inclan St, Miraflores, Lima 18, Peru

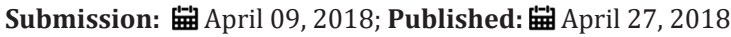

Keywords: Keywords: Magnesium; Hypomagnesaemia; Chronic kidney disease; Dialysis

Abbreviations: Mg: Magnesium, HD: HemoDialysis, PD: Peritoneal Dialysis, CVD: Cardio Vascular Disease

\section{Introduction}

In the normal population, total and ionized serum magnesium $(\mathrm{Mg})$ concentrations usually lie between 0.65 and $1.05 \mathrm{mmol} / \mathrm{L}$ and 0.45 and $0.74 \mathrm{mmol} / \mathrm{L}$, respectively. In HemoDialysis (HD) and Peritoneal Dialysis (PD) patients, both total and ionized magnesium concentrations are often slightly elevated above the normal range and have been shown to be dependent on residual renal function $[1,2]$. An understanding of the physiology in $\mathrm{Mg}$ handling is therefore of relevance for those taking care of patients with HD or PD [3].

\subsection{Hypomagnesaemia and mortality in dialysis}

A growing body of literature associate hypomagnesaemia with important clinical end points such an increased risk of Cardio Vascular Disease (CVD), comorbidity and mortality [3]. Ishimura [4] investigated the prognostic value of serum magnesium concentration for mortality in 515 patients on HD (age $60 \pm 12$ years, 306 males and 209 females; 24\% diabetics). The patients under went follow-up for $51 \pm 17$ months. During the follow-up period, there were 103 all-cause deaths, including 63 non-cardiovascular deaths. Multivariate Cox proportional hazard analysis demonstrated that serum magnesium was a significant predictor for mortality (HR (per 1mg/dL increase), 0.485 [95\% CI, 0.241-0.975), $\mathrm{p}=$ 0.0424 ), particularly for non-cardiovascular mortality (HR 0.318 [95\% CI, 0.132 to 0.769), $p=0.0110$ ), after adjustment for other confounders, such as age, gender, HemoDialysis duration, and the presence of diabetes.

Finally, lower serum magnesium level is a significant predictor for mortality in HD, particularly for non-cardiovascular mortality, although the mechanisms remain to be explored in future studies. Sakaguchi [5] conducted a nationwide registry based cohort study of 142555 Japanese HD patients. During follow-up 11,454 deaths occurred, of which 4774 had a CVD cause, so mortality accounted for $41.7 \%$ of deaths; hypomagnesemia was significantly associated with an increased risk of mortality in hemodialysis patients.
Interventional studies are needed to clarify whether magnesium supplementation is beneficial for improving patient prognosis. Lacson [6] investigated 7,544 HD patients in the followup study, there were 4,531 deaths. In Cox proportional hazards models, there was a linear decline in death risk from the lowest to the highest serum magnesium category, with the best survival at serum magnesium levels $>2.50 \mathrm{mEq} / \mathrm{L}$ (HR, 0.68; 95\%CI, 0.560.82). Elevated serum magnesium levels $>2.10 \mathrm{mEq} / \mathrm{L}$ were associated with better survival than low serum magnesium levels $<1.30 \mathrm{mEq} / \mathrm{L}$ in HD patients. Prospective studies may determine whether manipulation of low serum magnesium levels affects survival.

Li [7] investigated 9,359 HD patients, among patients with low albumin level $(<3.5 \mathrm{~g} / \mathrm{dL})$ and magnesium level $<2.0 \mathrm{mg} / \mathrm{dL}$ were associated with an additional death risk (adjusted HR, 1.17; 95\%CI, 1.05-1.31; $\mathrm{P}=0.004)$. Fein [8] conducted a study and enrolled 62 PD patients. Mg levels $<0.8 \mathrm{mmol} / \mathrm{L}$ at enrollment were associated with a higher relative risk of death. During the follow-up period, 27 patients died (43.5\%). Multivariate Cox regression analysis revealed that serum magnesium is a significant predictor of mortality (RR: 0.984; $\mathrm{p}=0.048$ ) after adjusting for age, race, sex, diabetes, and months on dialysis at enrollment. Yang [9] conducted a study of 10682 PD patients, the higher risk for hospitalization persisted upon adjustment for laboratory variables, whereas that for all-cause mortality was attenuated to a non significant level. The greatest risk for hospitalization was in patients with low serum albumin levels $(<3.5 \mathrm{~g} / \mathrm{dL} ; \mathrm{p}<0.001)$. There are many factor in PD, such as inflammation and nutritional status that have been linked with magnesium

Cai [10] evaluated 253 PD patients, 36 patients (14.2\%) suffered from hypomagnesemia. During amedian follow-up of 29 months (range: 4-120 months), 60 patients (23.7\%) died, and 35(58.3\%) of these deaths were attributed to cardiovascular causes. Low serum 
magnesium was positively associated with peritoneal dialysis duration $(r=0.303, p<0.001)$ as well as serum concentrations of albumin $(\mathrm{r}=0.220, \mathrm{p}<0.001)$, triglycerides $(\mathrm{r}=0.160, \mathrm{p}=$ $0.011)$, potassium $(r=0.156, p=0.013)$, calcium $(r=0.299, p<$ $0.001)$ and phosphate $(r=0.191, p=0.002)$. In a multivariate Cox proportional hazards regression analysis, serum magnesium was an independent negative predictor of all-cause mortality (Hazard Ratio (HR) $=0.075, \mathrm{p}=0.011)$ and cardiovascular mortality (HR = $0.003, p<0.001$ ), especially in female patients.

\section{Conclusion}

In dialysis patients there are few studies have concentrated on the role that altered Mg homeostasismay play. The limited evidence that exists on the relationship between $\mathrm{Mg}$ and outcomes about mortality. It remains unclear whether the link between $\mathrm{Mg}$ and clinical outcomes in dialysis patients is causal or associative. Further studies among HD and PD patients are warranted to explore whether there is an optimal range of serum $\mathrm{Mg}$ at which cardiovascular outcomes, hospitalization and survival are optimized.

\section{References}

1. Cunningham J, Rodriguez M, Messa P (2012) Magnesium in chronic kidney disease Stages 3 and 4 and in dialysis patients. Clin Kidney J 5(Suppl 1): i39-i51.
2. Misra Paraish S, Nessim Sharon J (2017) Clinical aspects of magnesium physiology in patients on Dialysis. Semin Dial 30 (5): 438-445.

3. Van de Wal-Visscher ER, Kooman JP, Van der Sande FM (2018) Magnesium in Chronic Kidney Disease: Should We Care? Blood Purif 45(1-3): 173-178.

4. Ishimura E, Okuno S, Yamakawa T, Inaba M, Nishizawa Y (2007) Serum magnesium concentration is a significant predictor of mortality in maintenance hemodialysis patients. Magnes Res 20(4): 237-244.

5. Sakaguchi Y, Fujii N, Shoji T, Hayashi T, Rakugi H, et al. (2014) Hypomagnesemia is a significant predictor of cardiovascular and noncardiovascular mortality in patients undergoing hemodialysis. Kidney Int 85(1): 174-181.

6. Lacson E Jr, Wang W, Ma L, Passlick-Deetjen J (2015) Serum magnesium and mortality in hemodialysis patients in the United States: a cohort study. Am J Kidney Dis 66(6): 1056-1066.

7. Li L, Streja E, Rhee CM, Mehrotra R, Soohoo M, et al. (2015) Hypomagnesemia and mortality in incident hemodialysis patients. Am J Kidney Dis 66(6): 1047-1055.

8. Fein P, Weiss S, Ramos F, Singh P, Chattopadhyay J, et al. (2014) Serum magnesium concentration is a significant predictor of mortality in peritoneal dialysis patients. Adv Perit Dial 30: 90-93.

9. Cai K, Luo Q, Dai Z, Zhu B, Fei J, et al. (2016) Hypomagnesemia Is Associated with Increased Mortality among Peritoneal Dialysis Patients. PLoS One 11(3): e0152488.

10. Yang X, Soohoo M, Streja E, Rivara MB, Obi Y, et al. (2016) Serum magnesium levels, hospitalization, and mortality in incident peritoneal dialysis patients: a cohort study. Am J Kidney Dis 68(4): 619-627.
Creative Commons Attribution 4.0 International License

For possible submissions Click Here

\section{Submit Article}

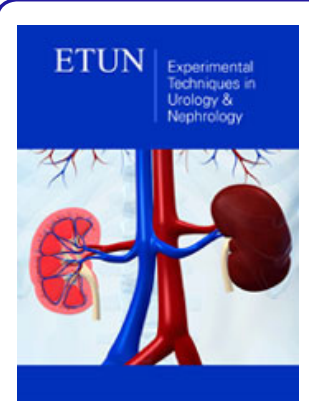

Experimental Techniques in Urology \& Nephrology

\section{Benefits of Publishing with us}

- High-level peer review and editorial services

- Freely accessible online immediately upon publication

- Authors retain the copyright to their work

- Licensing it under a Creative Commons license

- Visibility through different online platforms 